\title{
Role of Enhanced Detoxication in a Deltamethrin-resistant Population of Triatoma infestans (Hemiptera, Reduviidae) from Argentina
}

\author{
Paola González Audino, Claudia Vassena*, Silvia Barrios, Eduardo Zerba*, \\ María Inés Picollo/ ${ }^{+}$
}

Centro de Investigaciones de Plagas e Insecticidas, Juan Bautista de La Salle 4397 (B1603ALO) Villa Martelli, Buenos Aires,

Argentina *Escuela de Postgrado, Universidad Nacional de General San Martín, San Martín, Buenos Aires, Argentina

Deltamethrin and other pyrethroids have been extensively used in Argentina since 1980, for the chemical control of Triatoma infestans Klug (Hemiptera: Reduviidae). Recently, resistance to deltamethrin was detected in field populations by the survival of bugs exposed by topical application to the diagnostic dose estimated on the CIPEIN susceptible strain. Results of the current study showed low resistant ratios (RRs) to deltamethrin for the resistant populations (RR ranged from 2.0 for San Luis colony to 7.9 for Salta colony). Biochemical studies were made on the most resistant colony (Salta) and the susceptible strain (CIPEIN), in order to establish the importance of degradative mechanisms as a cause of the detected resistance.

Esterase activity was measured on 3 days old first instars through phenyl-thioacetate and $\alpha$-naphtyl acetate activities. The results showed a significant difference in no cholinesterase esterase activity from susceptible (7.6 \pm $0,7 \mu M$ S./i.min.) and Salta resistant colony $(9.5 \pm 0.8 \mu M$ S./i.min. $)$.

Cytochrome P450 mono-oxygenase (P450) activity was measured on individual insects through ethoxycoumarine deethylase (ECOD) activity using a fluorescence micro plate reader. The dependence of ECOD activity on age and body region of the nymphs, and $\mathrm{pH}$ and time of incubation were studied in order to optimize the measurement. As a result, comparative studies were performed on abdomens of 2 days old first instars at pH 7.2 and 4 h incubation time. ECOD activity of first nymphs was significantly lower in the susceptible colony $(61.3 \pm 9.08 \mathrm{pg}$ ECOD/ insect) than in the resistant one (108.1 $\pm 5.7 \mathrm{pg} E C O D /$ insect).

These results suggest that degradative esterases (no-cholinesterase) and mono-oxygenases cytochrome P450, play an important role in the resistance to deltamethrin in Salta colony from Argentina.

Key words: deltamethrin resistance - Triatoma infestans - cytochrome P450 mono-oxygenase - Argentina

Despite prolonged and intensive control campaigns against Chagas disease vectors, few studies have been reported on the possible development of insecticide resistance in triatomines (Nelson 1994). The first well documented evidence of field resistance was the resistance to dieldrin detected in Venezuelan Rhodnius prolixus from Trujillo, and later reported for the states of Yaracuy, Tachira, Cojedes, and Portuguesa from Venezuela (González Valdivieso et al. 1971, Cockburn 1972, Nocerino 1976). More recently, resistance to pyrethroid insecticides was reported in Brazilian Triatoma infestans from Rio Grande do Sul and a Venezuelan $R$. prolixus from Carabobo (Vassena et al. 2000). Resistance Ratios (RR) to the pyrethroids in the Brazilian colony could be associated to the intensive use of deltamethrin (RR 7), and cypermethrin (RR 3.3), and to the lower application of lambda-cyhalothrin (RR

Financial support: UNDP/World Bank/Special Programmer for Research and Training in Tropical Diseases and Consejo Nacional de Investigaciones Científicas y Técnicas de la República Argentina

${ }^{+}$Corresponding author. Fax: +54-11-4709.5334. E- mail: maryne@ febertel.com.ar

Received 30 December 2003

Accepted 5 May 2004
1.7). Otherwise the Venezuelan $R$. prolixus showed high resistance levels to all pyrethroids evaluated (RR from 11.4 for deltamethrin to 4.5 for lambda-cyhalothrin), and low resistance to dieldrin (RR 3), in spite of the use of cyclodienes for the control of $R$. prolixus in that state. Toxicological studies with the monooxygenase inhibitor piperonyl butoxide, demonstrated that the resistance to pyrethroids observed in resistant $T$. infestans and $R$. prolixus, was caused by an increase in the activity of the biodegradation enzymes.

In Argentina, a monitoring study for the detection of changes in the insecticide susceptibility of $T$. infestans field populations, was developed since 1997. Monitoring of deltamethrin resistance in collected insects from 13 provinces (170 samples), by the topical application of diagnostic dose $\left(\mathrm{DL}_{99}\right)$ for the susceptible CIPEIN strain, showed incipient resistance in 4 localities of Argentina: Mendoza, San Luis, Catamarca, and Salta (Picollo 2001). The deltamethrin resistance can be correlated with the National Campaigns for Vector Control made with this insecticide and other pyrethroids in those provinces. The deltamethrin resistance detected for these field samples was not yet correlated with failures in the field chemical control, but demonstrated the genetic potential for resistance in this species.

In this work, deltamethrin resistant levels were assessed in the Argentinean resistant colonies, and the es- 
terase and cytochrome $\mathrm{P} 450$ monooxygenase (P450) activity was studied, as a probable cause of resistance in the highest resistant field population (Salta).

\section{MATERIALS AND METHODS}

Insects - Resistant and susceptible T. infestans used in this study were obtained from our laboratory culture at $28 \pm 1{ }^{\circ} \mathrm{C}, 50 \% \mathrm{RH}$ and $12: 12 \mathrm{~h}$ (L:D) photoperiod (WHO 1994). CIPEIN is an susceptible strain maintained in our laboratory since 1975 without exposure to insecticides (Picollo et al. 1976). Deltamethrin resistant colonies were originated from field populations collected by specialized personnel of the National Campaigns for the Control of Chagas Vectors, and maintained in our laboratory. Mendoza colony was collected in Guaymallén, Mendoza in June 1997, San Luis colony in Belgrano, San Luis in July 1997, Catamarca colony in San Martín, Salta in September 1999. Deltamethrin resistance in these field populations was assessed at the time of collection by the appearance of alive nymphs treated with diagnostic dose of the insecticide for the susceptible strain (WHO 1994, Picollo 2001).

From all colonies, 3 days old, first instars, starved since eclosion (mean weight $1.2 \pm 0.2 \mathrm{mg}$ ) were selected for toxicity test, according the WHO protocol (1994). First and second instars, 3 days old and starved since eclosion, from CIPEIN and Salta colonies, were selected for esterase and P450 activity measurement. First instars from CIPEIN strain were used for studying the dependence of deethylase activity with $\mathrm{pH}$, incubation time, age, stadium, and body region.

Chemicals - Technical grade deltamethrin (97\% [AI], Aventis, Buenos Aires, Argentina). The 5,5' dithiobis-2nitrobenzoic (DTNB), 7-ethoxycoumarin (7-EC), 7hydroxycoumarin (umbelliferone), eserine and Fast Blue B were from Sigma (St. Louis, MO), Phenylthioacetate (PTA) and lauryl sodium sulphate from Aldrich (Milwaukee, WI). All solvents were analytical grade and purchased from Merck (Buenos Aires, Argentina)

Bioassays - Serial dilutions of deltamethrin in acetone were prepared and applied topically with a $10 \mu \mathrm{l}$ Hamilton micro syringe provided with a repeating dispenser. Each nymph was treated with $0.2 \mu \mathrm{l}$ of the solution on the ventral abdomen. Final dose ranged from 0.02 to 6 nanogram /insect.

Each concentration was replicated three times using 10 insects per replicate. Treated insects were placed onto filter paper discs and housed in an environmental chamber (Lab-Line Instruments, Melrose Park, IL), at $28 \pm 1^{\circ} \mathrm{C}$, $55 \pm 5 \% \mathrm{RH}$ and $12: 12 \mathrm{~h}$ photoperiod. Mortality was recorded at $24 \mathrm{~h}$ after treatment. The criterion for mortality was the inability of the nymphs to walk from the center to the border of a $7 \mathrm{~cm}$ filter paper disc (Vassena et al. 2000). Mortality data were corrected using Abbott formula (Abbott 1925).

Enzyme activity - Esterases were determined on first instars from susceptible and resistant populations according to Ellman's colorimetric method (Ellman 1961) adapted to T. infestans (Casabé \& Zerba 1981).

Phenylthioacetate (PTA)- The filtrated homogenate (100 $\mu \mathrm{l})$, and $300 \mu \mathrm{l}$ of phosphate buffer ( $\mathrm{pH} 7.2)$ contain- ing DTNB $(10 \mathrm{mg} / 100 \mathrm{ml})$, were added in a semi micro cell ( $500 \mu \mathrm{l}$ capacity). Reaction was started by adding $50 \mu \mathrm{l}$ of $20 \mathrm{mM}$ PTA. Changes in absorbance were measured for 5 $\min$ at $412 \mathrm{~nm}$ on a Shimadzu UV-160. Measurements were repeated after pre-incubation with $50 \mu 10^{-4} \mathrm{M}$ eserine for 15 min at $25^{\circ} \mathrm{C}$.

Alpha-naphtyl acetate $(\alpha-N A)$ - The color reagent was prepared just before the assay, by mixing 1 part of fast blue solution in phosphate buffer $0.2 \mathrm{M}$, and 5 parts of sodium dodecyl sulphate (SDS) 5\%. Filtered homogenate $(100 \mu \mathrm{l}), 1.4 \mathrm{ml}$ of phosphate buffer $0.2 \mathrm{M} \mathrm{pH} 7.2$, and 100 $\mu \mathrm{l}$ of $4 \mathrm{mg} / \mathrm{ml} \alpha$-NA, were added in the reaction tube. Samples were incubated at $30^{\circ} \mathrm{C}$ for $3 \mathrm{~min}$. At initial time and after 3 min of incubation $400 \mu \mathrm{l}$ of the mixture homogenate/substrate was added to $80 \mu 1$ of color reagent. After the 10 min necessary for the stabilization of the color, the absorbance was measured at $600 \mathrm{~nm}$.

Similarly, non cholinesterase esterase activity was measured after previous inhibition with eserine. For this, $1.25 \mathrm{ml}$ of the mixture homogenate and substrate, was incubated with $150 \mu \mathrm{l}$ eserine for $15 \mathrm{~min}$. After this period color reagent was added as described before.

Cytochrome P450 monooxygenase - Activity was measured using 7-ethoxycoumarin O-deethylation (ECOD) on intact tissue on micro plate reader (Bouvier et al. 1998). Fluorescence was determined using a micro plate fluorescence reader Packard Fluorocount, with $400 \mathrm{~nm}$ excitation and $440 \mathrm{~nm}$ emission filters.

First instar abdomens were placed individually into the wells of a 96-well micro plate containing $100 \mu \mathrm{l}$ of 0.05 $\mathrm{M}$ phosphate buffer, and 7- EC $0.04 \mathrm{mM}$. The reaction was stopped after incubation time by adding $100 \mu$ lof glycine buffer $\left(10^{-4} \mathrm{M}\right), \mathrm{pH} 10.4$. In order to bring down the abdomens in the wells, micro plates were centrifuged at $2000 \mathrm{~g}$ for $30 \mathrm{~s}$ in a refrigerated centrifuge for micro plates ALC $4237 \mathrm{R}$ prior to and after the incubation of the enzymatic reaction at $30^{\circ} \mathrm{C}$. For each population, similar wells receiving glycine buffer previous to incubation were used for blanks.

Statistical analysis - Dose-mortality data from each $T$. infestans colony were subjected to probit analysis (Litchfield \& Wilcoxon 1949). Lethal dose 50\% $\left(\mathrm{LD}_{50}\right)$ values obtained in probit were expressed as nanograms of deltamethrin per insect. After probit analysis, resistance ratios with 95\% CL (confidence limit) were calculated for each colony, by comparing results from resistant insects to corresponding results from the susceptible strain as described by Robertson and Preisler (1992).

Biochemical data were analyzed by analysis of variance (ANOVA) to assess significant differences in enzyme activity between susceptible and resistant population (Sokal \& Rohlf 1980).

\section{RESULTS}

The resistance ratio (RR) to deltamethrin for each resistant population relative to the CIPEIN susceptible strain, were established (Table I). All samples showed low resistance levels ranging from 2.0 to 7.9 . The highest resistant Salta colony was selected for biochemical studies.

The measured activity of esterases from susceptible (CIPEIN) and resistant (Salta) T. infestans colonies, was 
TABLE I

Bioassay statistics and resistant ratios (RR) for deltamethrin in field populations of Triatoma infestans from Argentina

\begin{tabular}{lcccc}
\hline Population & $\mathrm{n}$ & Slope $\pm \mathrm{SE}$ & $\mathrm{LD}_{50}(\mathrm{ng} / \mathrm{i})(95 \% \mathrm{CL})$ & $\mathrm{RR}(95 \% \mathrm{CL})$ \\
\hline CIPEIN & 145 & $1.76 \pm 0.25$ & $0.099(0.072-0.137)$ & - \\
Catamarca & 150 & $1.42 \pm 0.23$ & $0.266(0.181-0.385)$ & $2.679(1.660-4.324)$ \\
Mendoza & 160 & $1.97 \pm 0.25$ & $0.375(0.180-0.773)$ & $3.771(2.462-5.779)$ \\
San Luis & 145 & $1.95 \pm 0.28$ & $0.199(0.141-0.269)$ & $2.000(1.275-3.138)$ \\
Salta & 149 & $1.69 \pm 0.25$ & $0.784(0.553-1.077)$ & $7.891(4.999-12.455)$ \\
\hline
\end{tabular}

Topical application of $0.2 \mu \mathrm{l}$ acetone solution to dorsal abdomen of first instar (aged 3 days). $\mathrm{LD}_{50}$ value ng ai/nymph; RR $\pm 95 \% \mathrm{CI}$ calculated by method of Robertson and Preisler (1992); CIPEIN: susceptible laboratory strain

summarized in Table II. There was not difference between the total esterase activity from both colonies, using PTA or $\alpha$-NA as substrates. No significant differences were found between no-cholinesterase esterases (after eserine inhibition) for both colonies ( $\mathrm{p}>0.05)$ using $\alpha$-NA as substrate. Otherwise significant difference was found between esterase no-cholinesterase from susceptible and resistant populations using PTA as substrate $(\mathrm{p}=0.0006)$. Measured activity in resistant nymphs was higher than susceptible ones.

The optimal methodological and biological variables for measuring P450 activity were determined on $T$. infestans susceptible strain. Methodological variables studied were the $\mathrm{pH}$ of the incubation buffer and the reaction time. The results showed that the maximal reading of ECOD activity was obtained using $\mathrm{pH} 7.2$ (Figure) although the differences were no significant ( $p>0.05)$. Concerning incubation times, fluorescence increased with time increase and showed a plateau at an incubation time of 3$5 \mathrm{~h}$ (Figure). The biological variable studied was the age of $T$. infestans first instar. The ECOD activity measured on $1,2,3$, and 4 days old starved nymphs are shown in Figure. In spite of the lack of statistical significance, the results suggested a trend to maximal activity towards the second day after hatching. Moreover lesser dispersion in ECOD activity records was observed for 1 and 2 days old nymphs.

As a result of the described standardization according to the methodological and biological variables, we used abdomens of 2 days old first instars T. infestans, buffer $\mathrm{pH}$ 7.2, and $4 \mathrm{~h}$ incubation time. Under these conditions, deethylation of 7-ethoxycoumarin appeared signifi-

\section{TABLE II}

Esterase activity in susceptible CIPEIN and deltamethrin resistant Salta Triatoma infestans

\begin{tabular}{lcc}
\hline & \multicolumn{2}{c}{ Activity $(\mu \mathrm{M}$ S/insect . min) } \\
\cline { 2 - 3 } Substrate & CIPEIN & Salta \\
\hline Phenylthioacetate $(P T A)$ & $20.1 \pm 4.4^{\mathrm{a}}$ & $21.7 \pm 3.9^{\mathrm{a}}$ \\
PTA + eserine & $7.6 \pm 0.7^{\mathrm{a}}$ & $9.5 \pm 0.8^{\mathrm{b}}$ \\
$\alpha$-naphtylacetate $(\alpha-N A)$ & $40.8 \pm 16.2^{\mathrm{a}}$ & $43.3 \pm 14.4^{\mathrm{a}}$ \\
$\alpha-N A+$ eserine & $24.6 \pm 13.2^{\mathrm{a}}$ & $27.3 \pm 14.3^{\mathrm{a}}$
\end{tabular}

Substrate + eserine: esterase (no-cholinesterase) activity. Values followed by the same letter were not statistically different according to ANOVA cantly higher in the resistant colony than in the susceptible one (Table III). The enzyme activity ratio (R/S) between $\mathrm{R}$ and $\mathrm{S}$ colonies was 1.9. In spite of the significant difference of the higher ECOD activity of the Salta strain $(\mathrm{p}=0.03$ ) we attempted to confirm in another instars the difference in ECOD activity of T. infestans resistant and susceptible first instar. For that purpose we applied the fluorometric technique to measure ECOD activity, to 2 days old second instar of the resistant and susceptible populations. Results are shown in Table III. The higher ECOD
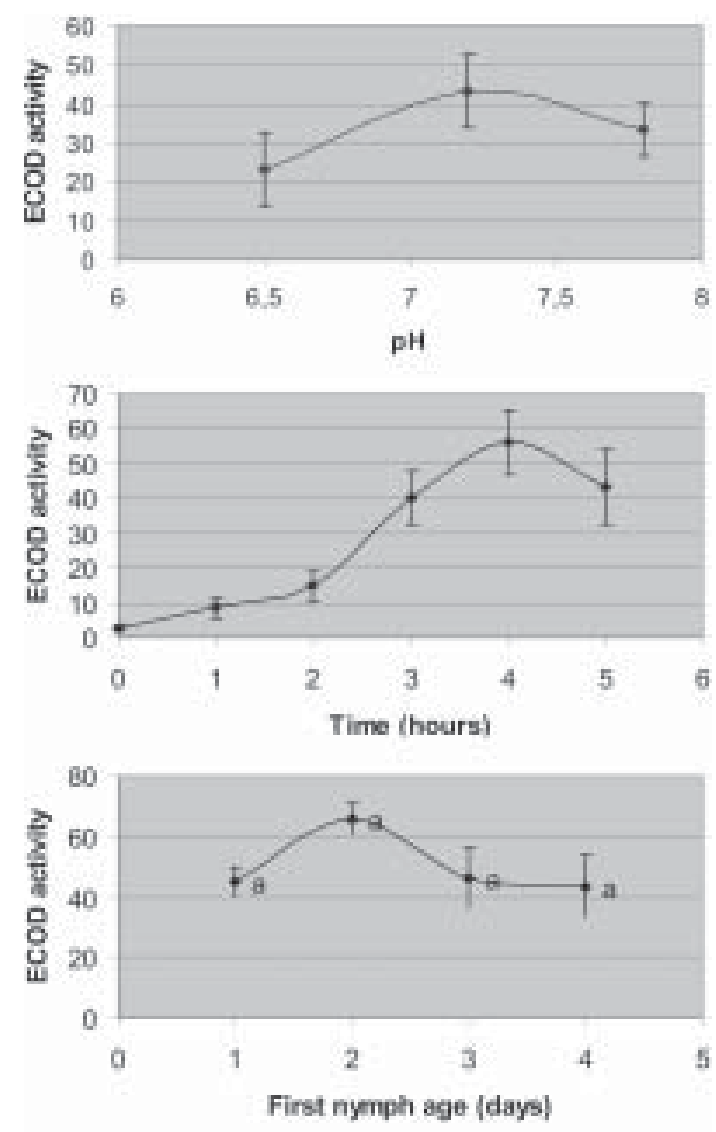

Influence of the buffer $\mathrm{pH}$, incubation time and nymph age on the 7-OH fluorescence intensity following incubation of 7-ETOC with nymph Triatoma infestans abdomens (CIPEIN strain). Values are the mean of 20 replicates (one abdomen/well) and are expressed as pg of 7-OH formed per abdomen per minute. Values followed by the same letter were not statistically different according to ANOVA analysis of the data. ECOD: ethoxycoumarine deethylase 
TABLE III

Ethoxycoumarine deethylase (ECOD) activity in CIPEIN susceptible and Salta deltamethrin resistant colonies.

\begin{tabular}{lcc}
\hline & \multicolumn{2}{c}{ ECOD activity* (pg 7-OH / m. insect) } \\
\cline { 2 - 3 } Colony & First nymph & Second nymph \\
\hline CIPEIN & $61.3 \pm 9.08^{\mathrm{a}}$ & $61.2 \pm 6.9^{\mathrm{a}}$ \\
Salta & $108.0 \pm 15.7^{\mathrm{b}}$ & $104.3 \pm 0.5^{\mathrm{b}}$ \\
\hline
\end{tabular}

ECOD activity measured on individual tests on nymph abdomens. Values followed by the same setter were not statically different according to ANOVA

activity was also observed in second instar of the Salta resistant population $(\mathrm{p}=0.006)$.

\section{DISCUSSION}

Since 1960's, the chemical control of Chagas disease vectors was based on insecticides (Zerba 1999). The continuous use of insecticides produced the development of resistance in $R$. prolixus field populations from Venezuela (Nocerino 1976, Vassena et al. 2000) and resistance to pyrethroids in T. infestans from Brazil (Vassena et al. 2000). An extensive monitoring of resistance was made in Venezuela (Molina \& Soto Vivas 2001), Colombia (Sandoval 2001), and Argentina (Picollo 2001). Resistance to deltamethrin was assessed in field populations from 4 localities of Argentina, by the survival of bugs exposed to the diagnostic dose $\left(\mathrm{LD}_{99}\right)$ of the susceptible strain.

Results of the current work, show low levels of resistance to deltamethrin in the 4 resistant populations. Resistant ratios relative to CIPEIN strain, ranged from 2.0 (San Luis) to 7.9 (Salta). The resistance level to deltamethrin in the highest resistant sample (Salta), was similar to those reported for Brazilian T. infestans (RR 7.0) and Venezuelan $R$. prolixus (RR 11.4). Resistance to pyrethroids in insects has been correlated with enhanced metabolism by enzymes (Oppenoorth 1985, Wilkinson 1983), and particularly a higher cytochrome P450s activity was measured in pyrethroid resistance in housefly (Lee \& Scott 1989). Hung \& Sun (1989), using ethoxycoumarine as substrate, found that larvae homogenates of fenvalerate resistant diamond moth, possessed 100 fold higher activity than susceptible insects. Bouvier et al. (1998) reported higher ethoxycoumarin deethylase activity measured at individual level in microtritation plates, in deltamethrin resistant Cydia pomonella.

Our results showed that the esterase activity measured on PTA and $\alpha$-NA substrates, showed only a significant difference in no-cholinesterase esterase from susceptible and resistant $T$. infestans populations. The Sa colony showed higher activity than the CIPEIN strain, suggesting that an enhanced degradation of deltamethrin by degradative esterases (no-cholinesterase), could contribute to resistance.

For determining P450 activity, abdomens were selected in our routine determinations because of the antecedents of the insect applications of this fluorometric technique and practical considerations about the first instars dis- sections. We found that the optimal results were performed with abdomens of 2 days old first nymphs, using buffer $\mathrm{pH} 7.2$ and $4 \mathrm{~h}$ incubation time. Differences of 2 folds were observed for ECOD activity between the Salta resistant and the CIPEIN susceptible colonies. These results suggest that a higher P450 activity of the Salta resistant colony observed in first and second instars could be a contributive cause of the resistance phenomena.

For biochemical studies we found that miniaturized and automated assays of P450 activity, offer some major advantages over conventional ones. It is simpler and more rapid because no substrate-product organic separation step is necessary before measuring. It is also much more performing since on microsomal preparations the ECOD assay sensitivity is usually many times lower (de Sousa et al. 1995). This great sensitivity allows the quantification of ECOD activities on whole individual insect abdomens directly placed in a micro titer plate well, without any prior preparation of microsomal membranes.

\section{ACKNOWLEDGEMENTS}

To Sonia Blanco and Mario Zaidemberg from the Ministry of Health of Argentina for the coordination of the insect sampling.

\section{REFERENCES}

Abbott WS 1925. A method of computing the effectiveness of an insecticide. J Econ Entomol 18: 265- 267.

Bouvier JC, Cuany A, Monier C, Brosse V, Sauphanor B 1998. Enzymatic diagnosis of resistance to deltamethrin in diapausing larvae of the codling moth Cydia pomonella (L.). Arch Ins Biochem And Physiol 39: 55-64.

Casabé N, Zerba E 1981. Esterases of Triatoma infestans and its relationship with the metabolism of organophosphorous insecticides. Comp Biochem Physiol 68C: 255-258.

Cockburn JM 1972. Laboratory Investigations Bearing on Insecticide Resistance in Triatomine Bugs, WHO/ 72.359, World Health Organization, Geneva.

De Souza G, Cuany A, Brun A, Amichot M, Rahmani R, Berge JB 1995. A microfluorometric method for measuring Ethoxycoumarin-O-deethylase activity on individual Drosophila melanogaster abdomens: interest for screening resistance in insect populations. Anal Biochem 229: 86-91.

Ellman GL, Courtney KD Andres, V Jr., Featherstone RH 1961. A new and rapid colorimetric determination of acetylcholinesterase activity. Biochem Pharmac 7: 88-95.

González-Valdivieso FE, Sánchez Diaz B, Nocerino F 1971. Susceptibility of Rhodnius prolixus to Chlorinated Hydrocarbon Insecticides in Venezuela, WHO/VBC/71.264, World Health Organization, Geneva.

Hung C, Sun H 1989. Microsomal monooxygenases in diamondback moth larvae resistant to fenvalerate and piperonyl butoxide. Pest Biochem Physiol 33: 168-175.

Lee S, Scott J 1989. Microsomal cytochrome P450 monooxygenases in the house fly (Musca Domestica L.). Biochemical changes associated with pyrethroid resistance and phenobarbital induction. Pest Biochem And Physiol 35: 110.

Lichfield JT, Wilcoxon FJ 1949. A simplified method of evaluating dose-effect experiments. J Exp Ther 96: 99-103.

Molina de Fernández DM, Soto de Vivas A 2001. Monitoreo de resistencia a insecticidas en cepas de campo de Rhodnius prolixus en Venezuela. In Monitoreo de la Resistencia a Insecticidas en Triatominos en América Latina, Fundación Mundo Sano, Buenos Aires, Argentina, pp. 33-39. 
Nelson MJ 1994. Experiencias en el monitoreo de niveles de susceptibilidad de los triatominos a los insecticides en las Americas. Acta Toxicol Argentina 2: 44-48.

Nocerino F 1976. Susceptibilidad de Rhodnius prolixus y Triatoma maculata a los insecticidas en Venezuela. Bol Direc Malariol San Ambiental, Venezuela 16: 276-283.

Oppenoorth FJ 1985. Biochemistry and genetics of insecticide resistance. In GA Kerkut, CI Gilbert (eds), Comprehensive Insect Physiology, Biochemistry and Pharmacology, Vol. 12, Pergamon Press, Oxford, UK, p. 731-773.

Picollo MI 2001. Avances en el monitoreo de resistencia a insecticidas en triatominos y necesidades futuras. In Monitoreo de la Resistencia a Insecticidas en Triatominos en América Latina, Fundación Mundo Sano, Buenos Aires, Argentina, p. 13-21.

Picollo MI, Wood EJ, Zerba EN, Licastro SA, Rúveda MA 1976. Laboratory test for measuring toxicity of insecticides in Triatoma infestans, Klug. Acta Bioquim Latinoam X : 67 70. In spanish.
Robertson JL, Preisler HK 1992. Pesticide Bioassays with Arthropods. CRC, Boca Raton, FL.

Sandoval CM 2001. Actividad insecticida del Malatión y la Deltametrina en una cepa colombiana de Rhodnius prolixus (Hemiptera, Reduvidae). In Monitoreo de la Resistencia a Insecticidas en Triatominos en América Latina, Fundación Mundo Sano, Buenos Aires, Argentina, p. 27-33.

Sokal R, Rohlf F 1980. Introducción a la Bioestadística, Editorial Reverté, Barcelona.

Vassena CV, Picollo MI, Zerba EN 2000. Insecticide resistance in Brazilian Triatoma infestans and Venezuelan Rhodnius prolixus. Med Vet Entomol14: 51-55.

Wilkinson CF 1983. Role of mixed function oxidase in insecticide resistance. In P Georghiou, T Saito (eds), Pest Resistance to Pesticide, Plenum Press. New York, p. 175-207.

WHO 1994. Protocolo de evaluación de efecto insecticida sobre triatominos. Acta Toxicol Arg 2: 29-32.

Zerba E 1999. Susceptibility and resistance to insecticides of Chagas disease vectors. Medicina 59: 41-46. 